\title{
ANÁLISE DO COMPORTAMENTO DA FRENTE PARLAMENTAR EVANGÉLICA NO BRASIL (2011-2015) ${ }^{1}$
}

\author{
Rodrigo Santos $^{2}$
}

Thiago Sampaio $^{3}$

\begin{abstract}
Resumo
Neste artigo discutimos em que medida os parlamentares religiosos, conhecidos por se associarem aos mais diversos partidos, têm oferecido algum tipo de obstáculo às iniciativas do Poder Executivo. Para analisar a Frente Parlamentar Evangélica (FPE) utilizamos a técnica de data-mining tendo como base as votações feitas pelos parlamentares da 54a legislatura (2011-2015). A partir daí criamos um indicador de coesão partidária e de vinculação ao governo da FPE (Ind_FPE). Identificamos que os políticos confessionais possuem atuação mais marcante em partidos catch-all e mantêm posição patogênica e egotrópica em relação ao funcionamento do processo legislativo.
\end{abstract}

Palavras Chaves: Comportamento legislativo; evangélicos; coesão partidária.

\begin{abstract}
In this article we discuss the extent to which religious parliamentarians, known for associating the various parties have offered some kind of obstacle to the initiatives of the Executive. To analyze the Frente Parlamentar Evangélica (FPE) used the data-mining technique based on the polls made by the 54th parliamentary term (2011-2015). From there we create a party cohesion index and link to the government of FPE (Ind_FPE). We found that the confessional politicians have performance that is more outstanding in catch-all parties and maintain pathogenic and egotrópica position relative to the functioning of the legislative process.
\end{abstract}

Key Words: Legislative behavior; evangelicals; party cohesion.

\section{Resumen}

En este trabajo se analiza el grado en que los parlamentarios religiosos, conocidos por estar asociados a muchas partes diferentes han ofrecido algún tipo de dificultad para las iniciativas del Poder Ejecutivo. Para analizar el Frente Parlamentario Evangélico se utilizó la técnica de minería de datos en base a las encuestas realizadas por los parlamentarios de la legislatura 54a (2011-2015). A partir de ahí creamos un indicador de la cohesión del partido y la vinculación con el gobierno de FPE (Ind_FPE). Hemos encontrado que los políticos confesionales tienen un desempeño más destacado en partidos catch-all y mantienen la posición patógena y egocéntrica en relación con el funcionamiento del proceso legislativo.

Palabras-clave: Comportamiento legislativo; evangélicos; la cohesión del partido.

\section{INTRODUÇÃO}

Nas últimas disputas eleitorais brasileiras cresceu o destaque dado a temas morais. Essa temática é embalada pelo aumento progressivo de eleitores do tipo confessional. Após a redemocratização, a participação cada vez mais incisiva por parte de denominações como

\footnotetext{
${ }^{1}$ DOI deste artigo: $10.5380 /$ recp.v6i2.42700.

2 Bacharel em Ciência Política pela Universidade Federal do Pampa (Unipampa)

${ }^{3}$ Doutor em Ciência Política (UFMG), professor adjunto do curso de Ciência Política da Universidade Federal do Pampa (Unipampa)
} 
Igreja Universal do Reino de Deus e, principalmente, Assembleia de Deus fez com que alguns partidos políticos direcionassem a sua agenda para esse segmento social.

O aumento significativo do capital político dos evangélicos reordenou forças no Congresso Nacional e possibilitou a criação da Frente Parlamentar Evangélica - FPE. A FPE, fundada em 2003, é formada conjuntamente pela participação de vários partidos e políticos unidos unicamente por comungarem dos mesmos valores, no caso, oriundos da tradição ocidental-cristã. Popularmente conhecida como "Bancada Evangélica”, a FPE não apresenta estrutura ideológica partidária para forçar seus participantes a seguirem determinada conduta política.

Essa talvez hipotética possibilidade da falta de um partido refere-se ao preâmbulo da inexistência de uma identidade política que aglomere os partidários identificados com essa causa. Borges (2009, p. 167), por exemplo, ao analisar este mesmo ponto, identifica a "ausência de traços em comum entre os membros" (evangélicos) como fator determinante para que não seja ainda possível notar a presença de um único partido que defenda as demandas desse seguimento. É importante ressaltar com isso que a formação de um partido pode estar ligada a vários fatores e não tão somente a questão reduzida à existência ou não de identidade, mas isso não deixa de ser um claro fator que influencia a construção de uma unidade partidária.

No cenário atual, fruto talvez de uma crise institucional dos partidos políticos brasileiros, as igrejas petencostais e neopetencostais atuam como proto-partidos. Por não se verem representados pelos partidos, os cidadãos recorrem a movimentos religiosos que atuam como organizações que identificam e representam interesses (BAQUERO; AMORIM, 2007). Isso aliado ao aparato midiático que as igrejas construíram facilita a atuação delas como porta-vozes do crescente número de evangélicos do país.

O reflexo desse processo é o aumento de cadeiras ocupadas por políticos declaradamente confessionais, de maioridade pentecostal/radical, na Câmara dos Deputados. Por comungarem da mesma compreensão sobre um conjunto de questões políticas, esses atores formam um bloco bastante coeso. O alicerce dessa coesão não está na disciplina obtida através de controle estruturado em recompensas e punições. Ela se mantém pelas perspectivas compartilhadas que os atrela a um conjunto de objetivos a serem 
perseguidos. A raiz da coesão entre os políticos confessionais está nos valores daqueles que eles representam.

Diante disso, aqui analisamos, a partir de votações de interesse da bancada e de interesse geral, em que medida os parlamentares evangélicos têm, de fato, se comportado estrategicamente perante o governo. Tais parlamentares podem ser identificados como individualistas ou partidários? Governistas ou oposição?

\section{COMPORTAMENTO LEGISLATIVO DA BANCADA EVANGÉLICA}

A estrutura do sistema político brasileiro fornece péssimas condições no que tange a governabilidade democrática. Isso devido aos obstáculos criados pelos partidos à atuação do executivo (PEREIRA \& MUELLER, 2003). O principal entrave surge das altas taxas de fragmentação e as regras eleitorais que privilegiariam o individualismo presente (AMES, 1995, 2003; MAINWARING, 1999; MAINWARING \& SHUGART, 1997; MAINWARING \& SCULLY, 1995; HAGGARD, 1995; HAGGARD E KAUFMAN, 1992; LAMOUNIER, 1989). Por esse motivo, as predileções fundamentais dos parlamentares na arena legislativa seriam organizadas exclusivamente por motivações relacionadas aos seus respectivos apoios na arena eleitoral, em especial no que concerne aos objetivos claros visando à própria reeleição (MAYHEW, 1974).

Este modelo explicativo, por sua vez, ficou conhecido como "two-arena modep" e procurou responder às questões relativas ao padrão de comportamento dos políticos dentro da atividade legislativa. Assim como Downs (1999), que também concede grandes somas de importâncias à ação dos políticos, esta visão põe em segundo plano a importância fundamental dos partidos no parlamento. Neste caso, o fato problemático é que, "havendo uma redução da importância dos partidos na arena eleitoral, estes também perdem funcionalidade no Parlamento, o que reduz os benefícios de um parlamentar em manter-se integrante de determinada linha de conduta partidária durante a legislatura" (CERVI 2009, 159). A noção simples dessa orientação diz que há ascendência da arena eleitoral sobre a arena legislativa, ou dita de outra forma, uma "conexão eleitoral" entre eleitores e atividade parlamentar. Isso é o mesmo que dizer que as atuações estratégicas dos atores dependem de sua própria necessidade de reeleger-se mais do que agir em prol de interesses programáticos definidos pelos seus respectivos partidos políticos. 
Por outro lado, há um convicto ceticismo contra esse pessimismo, já que são fracas as evidências que confirmam a debilidade do sistema político brasileiro, em especial o que descreve o comportamento dos políticos nacionais como reflexo de uma estrutura partidária incipiente e altamente fragmentada. $\mathrm{O}$ aporte fundamental de tal afirmação reside nos mecanismos institucionais que o próprio Poder Legislativo teria sobre a atuação individual dos parlamentares, principalmente em relação a uma estrutura de incentivos que resolveria o problema da ação coletiva ao fornecer restrições de regras que favoreceriam condutas de cooperação (FIGUEIREDO \& LIMONGI, 1995, 1997, 1999, 2000， 2002; MENEGHELLO, 1998; PEREIRA \& MUELLER, 2000; AMORIM \& SANTOS, 2001; AMORIM, 2002).

Em último caso, o próprio sistema concederia ao Poder Executivo às condições essenciais para fazer valer a sua vontade diante do Congresso. Assim, os pressupostos defendidos essencialmente pelos adeptos da "conexão eleitoral" esbarrariam em evidências que comprovariam o real funcionamento da atividade legislativa, a saber, a força dos partidos políticos na estruturação das preferências parlamentares.

Assim, o "one arena-model' surge para apontar que o comportamento dos parlamentares na arena legislativa seria determinado pelo constrangimento institucional imposto por mecanismos centralizadores dentro do Congresso, o que, por sua vez, retomaria a primazia dos partidos políticos sobre a ação individual dos parlamentares (BOWLER, 2000; COX, 1987; COX \& MCCUBBINS, 1993). Uma das implicações a se levar em consideração nesse modelo seria o que Cervi $(2009,160)$ apontou como sendo de natureza fundamental para se compreender a atuação particular dos parlamentares quanto aos seus objetivos eleitoreiros. São questões relevantes que poderiam dar conta do outro lado da moeda, já que este modelo implica não necessariamente uma “conexão eleitoral” Neste modelo, se ocorre, a conexão eleitoral é sempre indireta.

Além dessas duas abordagens predominantemente utilizadas e difundidas, Pereira e Muller (2003) propuseram uma terceira alternativa explicativa para o comportamento parlamentar e partidário. De acordo com a proposta, os argumentos utilizados anteriormente apontam para uma incompletude em ambos os modelos, considerados, nos termos dos autores, "parcial" e "incompleto". Esta diz que, o sistema político brasileiro funcionaria utilizando-se dos aspectos contraditórios de ambas as forças. 
O ponto fundamental da alegação é de que o sistema não seria nem inteiramente descentralizado (two arena-model), como o primeiro modelo propõe, nem inteiramente centralizado (one arena-model), como o segundo sugere; pelo contrário, seria uma união de duas partes sumarizadas em uma só; funcionando como dois elementos químicos que se complementam para o funcionamento de um organismo. Enquanto as regras eleitorais, o multipartidarismo e o federalismo agiriam como agentes descentralizadores do sistema; as regras internas do Congresso, os dispositivos institucionais e competências legislativas e delegativas do presidente agiriam contrariamente, promovendo a centralização.

Desse modo, Pereira e Mueller (2003) procuram comprovar que os políticos que formam principalmente a base aliada do governo tenderiam a votar de acordo com as orientações partidárias. Isso porque o Executivo controlaria os benefícios que supostamente garantiria as prebendas às suas respectivas bases eleitorais, o que consequentemente promoveria suas reeleições. Assim, na tentativa de angariar fundos aos seus redutos eleitorais, bem como indicações a cargos importantes, os parlamentares optariam sempre que possível pela busca do benefício por meio dos partidos políticos.

Um desses benefícios tem sido a prerrogativa Congressual de emendar o Orçamento. A análise comum é de que as emendas parlamentares, especificamente as emendas individuais ${ }^{4}$, forneceriam as bases que possibilitariam a compreensão desta noção de que votos seriam trocados por apoio ao Executivo. Pereira e Mueller (2002, 274), por exemplo, tem dito que o executivo "recompensa os parlamentares que sistematicamente votam a favor dos projetos de interesse do governo, autorizando a execução de suas emendas individuais, e, ao mesmo tempo, pune os que não votam nesses projetos simplesmente não executando as emendas propostas por eles".

Porém, Figueiredo e Limongi (2005, 741), mostraram que "tal visão desconsidera a realidade partidária que divide os parlamentares entre os que apoiam e os que se opõem ao governo". Na visão deles, não é possível encontrar uma relação exata entre apoiar o governo em troca de benefícios orçamentários. Isso porque dados analisados, entre 1996 e 2001, indicariam que "emendas são executadas sem que os votos esperados sejam dados, e votos

\footnotetext{
${ }^{4}$ As emendas individuais não são as únicas maneiras que os parlamentares possuem de participar da definição do orçamento, e, para Figueiredo e Limongi (2005), sequer são as principais. Somadas e ela, existem as emendas dos relatores e as emendas coletivas. De acordo com eles, dados de 1996 a 2001 comprovam que entre as três, ela é a menos executada, girando em um valor de 59,6\%; ao contrário das emendas por comissões e por relatoria, que teriam $78 \%$ e $65,4 \%$ das execuções, respectivamente.
} 
são dados sem que a contrapartida - ou seja, a liberação de recursos - ocorra" (FERNANDO \& LIMONGI, 2005, p. 740). A explicação dada para a ausência de correlação seria o fato de que o Executivo acomodaria as demandas dos parlamentares no seio de seu próprio programa, o que explicaria, por outro lado, a prática de beneficiar, inclusive, setores da oposição.

No caso dos parlamentares evangélicos, acreditamos que não seja muito diferente. Não tendo uma correlação positiva significativa entre apoiar o governo e receber mais emendas, na prática, existem fracas evidências que eles de fato se comportam estrategicamente em relação ao Executivo em troca de benefícios especificamente orçamentários, o que a princípio não quer dizer muito, em especial levando-se em consideração que os benefícios não se resumem apenas à execução de emendas que compreendem somente $1 \%$ de todo o orçamento, e sim, a possíveis apoios políticos governamentais junto às suas respectivas bases eleitorais. No Quadro 1 temos um exemplo sobre a média de execução de emendas individuais no ano de 2011.

Quadro 1 - Média de Execução de Emendas Individuais de 2011 segundo a posição político-partidária em relação ao Executivo

\begin{tabular}{|c|c|c|}
\hline \multirow{2}{*}{} & \multicolumn{2}{|c|}{ Posição Partidária em 2011 } \\
\cline { 2 - 3 } & Situação & Oposição \\
\cline { 2 - 3 } & Média & Média \\
\hline Valor de Execução de Emendas em 2011 & $\mathrm{R} \$ 5.823,553$ & $\mathrm{R} \$ 5.615,062$ \\
\hline
\end{tabular}

Fonte: Banco de Dados da Comissão Mista de Orçamento do Congresso

Além do mais, a ideia, formulada por Pereira e Muller (2003, 738-739), de que "o comportamento partidário na arena legislativa visa a que os seus membros extraiam benefícios individuais controlados pelo executivo" pressupõe que, antes de tudo, seja aceita a noção de que os partidos buscariam sempre o benefício político que encontra-se sob controle do Executivo, quando na verdade, isso desconsidera posições político-partidárias que são anteriores aos benefícios. No geral, se o cenário fosse de fato este, a saber, que o comportamento partidário ${ }^{5}$ tendesse a buscar unicamente os benefícios para os seus

\footnotetext{
${ }^{5}$ A diferença entre este modelo e o primeiro consiste na atuação dos líderes partidários na arena legislativa. Neste, as legendas são consideradas fortes e agem apenas na busca pelos interesses de seus adeptos; ao passo
} 
integrantes, raramente teríamos baixo apoio legislativo às pretensões do governo. O que não é o caso desta $54^{a}$ legislatura, onde a taxa média de apoio ao legislativo entre todos os partidos não tem se revelado tão elevada, conforme mostraremos.

\section{METODOLOGIA}

O voto nominal não representa e nem revela todos os detalhes sobre os determinantes do comportamento legislativo no Congresso - os projetos apreciados, votados ou rejeitados pelas comissões é um caso perfeito disso -, mas oferece importantes informações a respeito (NEIVA, 2011; PEREIRA \& MUELLER, 2003; FIGUEIREDO \& LIMONGI, 2005). Como por exemplo, possibilita compreender o registro público de determinada opção parlamentar por uma política em comparação com as orientações de seu partido e da presidência.

Assim, a partir de programação data-mining, criamos um indicador de apoio ao governo, que entre outras coisas, consistiu na recodificação das possibilidades de votos dos parlamentares entre um (1), totalmente A FAVOR, e zero (0), totalmente CONTRA. Essa ação tornou possível estimarmos o comportamento da FPE em relação ao posicionamento do governo, já que a contingência de comportamento no geral vai além dessa dicotomia.

Geralmente, quando há votações nominais em plenário, as alternativas vão muito além do SIM ou NÃO, isso porque parte-se do princípio de que qualquer player, antes de tudo, é possivelmente um maximizador de utilidade. Muitos parlamentares, às vezes, na tentativa de não se comprometerem politicamente com o seu partido ou mesmo com o governo, utilizam a alternativa de se ausentar do que propriamente a opção por um voto direto. O cálculo, nesses casos, seria o que poderíamos chamar de voto individualista - e quase sempre ele se direciona em favor do Poder Executivo - em especial quando se tem o conhecimento de que no Brasil é ele quem detém e controla, por meio de mecanismos internos, a maioria dos benefícios.

Os mecanismos que permeiam o congresso nacional são extremamente centralizadores. No Brasil, por exemplo, além dos próprios poderes constitucionais que o presidente tem para governar, há pelo menos duas maneiras utilizadas constantemente pelo

que no primeiro não, elas são consideradas fracas porque os parlamentares agem independentemente de seus líderes. 
Executivo para constranger os parlamentares a cooperar com as suas preferências, são eles: 1) a centralização da distribuição de recursos políticos e financeiros e; 2) a centralização do processo decisório pelos líderes partidários da coalização majoritária. No geral, são eles que procuram garantir a estruturação dos votos parlamentares no Congresso. Assim, é importante que se tenha atenção à posição que o Executivo toma em cada matéria votada na Câmara dos Deputados para que, em seguida, se possa estimar o comportamento de quem vota.

No nosso caso, ficou estabelecido que quando a posição do governo for favorável a uma matéria, haverá apenas uma possibilidade pró-governo, que é SIM, e quatro contrárias, que é NÃO, ABSTENÇÃO, AUSÊNCIA E OBSTRUÇÃO; sendo que em circunstâncias opostas, haverá quatro possibilidades pró-governo e uma contrária, conforme nos mostra a Figura 1; lembrando que, o indicador de adesão ao governo varia de 0 a 1, onde 1 é obtido pelos parlamentares que se mantiveram ao lado do governo em todas as votações e 0 por aqueles que nenhuma vez compartilharam da mesma posição apresentada pelo executivo.

Figura 1 - Alternativas de comportamento de voto em relação à orientação do Executivo

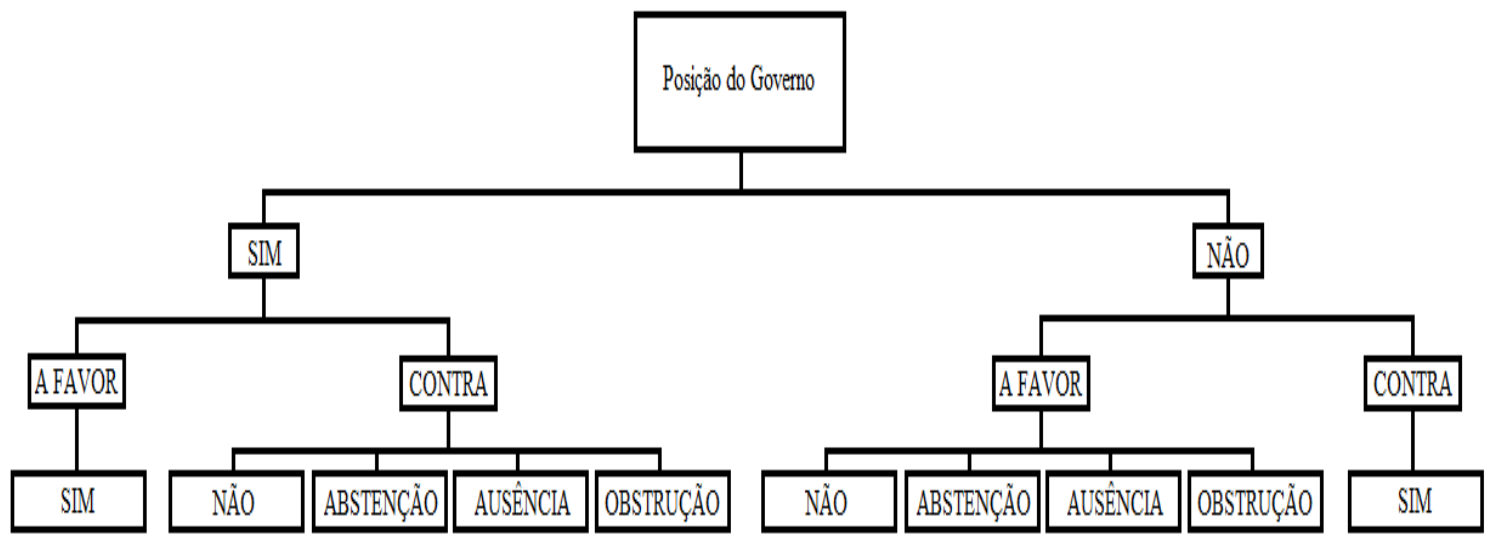

Fonte: Elaboração própria.

\section{COMPOSIÇÃO RELIGIOSA E PARTIDÁRIA DA FPE}

A Frente Parlamentar Evangélica não é composta por um grupo homogêneo específico. Pelo contrário, ela é o resultado de uma série de fenômenos e transformações externas que influenciaram a conjuntura do que chamamos atualmente de matriz religiosa protestante no Brasil. A prova disso é a quantidade significativa de igrejas que hoje permeiam o espaço institucional brasileiro. 
Por exemplo, na política, em função de várias características e condições diferentes, nem todos os grupos religiosos fazem parte da FPE. Alguns, inclusive, sequer cogitam essa possibilidade. "Deus é Amor", nesse caso, é uma delas. Isso porque suas próprias crenças e práticas religiosas os afastam de qualquer relação mais horizontalizada com alguma instituição propriamente política, como é o caso dos processos eleitorais e dos partidos políticos - muito utilizados ultimamente pelas igrejas como formas de estabelecer poder e influência. Outras, por outro lado, até pelo crescimento exponencial de seus adeptos, demonstram cada vez mais estarem dispostas a incluírem em suas fileiras fiéis comprometidos com suas demandas um tanto quanto conservadoras. Casos, por exemplo, da igreja Assembleia de Deus, Batista ${ }^{6}$ e Igreja Universal do Reino de Deus - IURD que, juntas, somam mais de 50\% dos parlamentares da FPE que possuem algum tipo de ligação com suas doutrinas eclesiais. Dessas, inclusive, a IURD é a que mais cresce, já que sua doutrina é a que menos se opõe a qualquer tipo de busca por alianças político-partidárias (ver Tabela 1).

${ }^{6} \mathrm{O}$ que é convencionalmente conhecido como Igreja Batista não se trata de uma instituição específica e sim várias. Aqui designamos como Batista aqueles pertencente a correntes vinculadas a Convenção Batista Brasileira. Outras correntes aparecerão com seus respectivos epítetos. 
Tabela 1 - Filiação religiosa dos parlamentares da FPE

$(2011-2014)$

\begin{tabular}{|c|c|c|}
\hline Filiação Religiosa & $\mathrm{N}$ & $\%$ \\
\hline Assembleia de Deus & 22 & 30,1 \\
\hline Batista & 9 & 12,3 \\
\hline Universal do Reino de Deus & 7 & 9,6 \\
\hline Presbiteriana & 4 & 5,5 \\
\hline Presbiteriana Independente & 3 & 4,1 \\
\hline Evangelho Quadrangular & 3 & 4,1 \\
\hline Internacional da Graça de Deus & 3 & 4,1 \\
\hline Comunidade Evangélica Sara Nossa Terra & 3 & 4,1 \\
\hline Não Declarado & 2 & 2,7 \\
\hline Metodista & 2 & 2,7 \\
\hline Cristã Maranata & 2 & 2,7 \\
\hline Batista Solidária & 1 & 1,4 \\
\hline Batista Getsêmani & 1 & 1,4 \\
\hline Batista Nacional & 1 & 1,4 \\
\hline Batista Independente & 1 & 1,4 \\
\hline Batista Caminho das Árvores & 1 & 1,4 \\
\hline Presbiteriana Renovada & 1 & 1,4 \\
\hline Luterana & 1 & 1,4 \\
\hline Renascer & 1 & 1,4 \\
\hline Nova Vida & 1 & 1,4 \\
\hline Cristã Evangélica & 1 & 1,4 \\
\hline O Brasil para Cristo & 1 & 1,4 \\
\hline Cristã do Brasil & 1 & 1,4 \\
\hline Mundial do Poder de Deus & 1 & 1,4 \\
\hline Total & 73 & 100,0 \\
\hline
\end{tabular}

Ao todo, incluindo aqueles que não possuem filiação declarada, eles totalizam um número aproximado ${ }^{7}$ de 73 deputados federais oriundos de mais de 20 denominações diferentes, onde a Assembleia de Deus é quem detém o maior número de filiados (22 parlamentares), seguido pelos históricos batistas (9 parlamentares) e pelos neopentecostais iurdianos (7 parlamentares). Os demais são compostos por denominações menores, inclusive, no cenário nacional. Essa classificação torna-se fundamental na medida em que temos como interesse a comparação do comportamento parlamentar entre os diferentes grupos religiosos.

A falta de identidade política comum resulta na ausência de uma sigla que defenda exclusivamente as demandas dos evangélicos. Como efeito tem-se a dispersão dos

\footnotetext{
${ }^{7}$ Devido as constantes mudanças que ocorrem dentro do parlamento, como é o caso das nomeações e das suplências, estamos utilizando o termo "aproximadamente". Infelizmente, nem todos os parlamentares acabam assumindo seus mandatos. Há muitos, inclusive, que durante toda a legislatura são substituídos por suplentes, isso quando não ficam flutuando em alterações repetitivas, alternando presenças em determinado conjunto de votações e ausências em outros - o que acaba dificultando muito a identificação de quem vota.
} 
representantes desse público em diversos partidos. Porém, é preciso considerar que antes o sucesso dos religiosos dava-se por meio da transformação do capital econômico em capital político; hoje, principalmente por meio da midiatização promovida pelas igrejas, a maior parte dos políticos confessionais tem transformado capital religioso em capital político (CAMPOS, 2005). Assim, os grupos religiosos com maior espaço nos veículos de comunicação mantêm o maior número de representantes no congresso.

Cada denominação evangélica apresenta a tendência de concentrar seus representantes em um único partido catch all de sua preferência. Conforme a Tabela 2, os partidos que concentram o maior número de membros da FPE são: Partido Social Cristão (PSC), Partido da República (PR) e Partido Republicano Brasileiro (PRB). Sendo o PRB aglutinador dos parlamentares ligados a Igreja Universal do Reino de Deus.

Tabela 2 - Composição partidária atual da bancada evangélica

\begin{tabular}{|c|c|c|}
\hline Partido & $\mathrm{N}$ & $\%$ \\
\hline PR & 11 & 15,3 \\
\hline PSC & 9 & 12,5 \\
\hline PRB & 9 & 12,5 \\
\hline PMDB & 8 & 11,1 \\
\hline PSD & 7 & 9,7 \\
\hline PSDB & 6 & 8,3 \\
\hline PTB & 4 & 5,6 \\
\hline PDT & 3 & 4,2 \\
\hline DEM & 2 & 2,8 \\
\hline PV & 2 & 2,8 \\
\hline PTdoB & 2 & 2,8 \\
\hline $\mathrm{PP}$ & 2 & 2,8 \\
\hline PSB & 2 & 2,8 \\
\hline $\mathrm{PT}$ & 2 & 2,8 \\
\hline PSL & 1 & 1,4 \\
\hline PRTB & 1 & 1,4 \\
\hline PTC & 1 & 1,4 \\
\hline Total & 72 & $\overline{100,0}$ \\
\hline
\end{tabular}

A preferência por partidos catch-all decorre da baixa rigidez ideológica presente nessas agremiações. Isto permite maior liberdade para votar segundo a convicção nas questões confessionais. Independente disso, como veremos a seguir, verificamos que a bancada evangélica é governista independentemente de partido político. Inclusive, a maior parte dos partidários da oposição (adeptos da FPE) votam mais com o governo do que seus próprios colegas de partido (não-adeptos). 


\section{FPE E A ADESÃO AO EXECUTIVO}

O comportamento dos parlamentares evangélicos não prima pela disciplina partidária. Entre eles, há a tendência de apoiar o Executivo sem considerar as determinações das lideranças partidárias. Os evangélicos membros do Partido da Social Democracia Brasileira (PSDB) são um bom indicativo desse comportamento, pois considerando que o partido é declaradamente oposição ao governo (ver Tabela 3) esses componentes mantêm posição contrária. No caso do PSDB, ao comparar o voto dos membros da FPE com aqueles que não pertencem a bancada vemos de imediato uma tendência pró-governo entre os religiosos que, embora sendo tênue, é evidente.

É perceptível a presença de um padrão de votação entre os evangélicos que os afasta da média daqueles que não pertencem a FPE. Em sua maioria, eles são declaradamente mais governistas do que os demais e demonstram possuir maior interesse em votar segundo as pretensões do executivo do que os seus correligionários de partido. Em onze dos dezessete partidos com representantes na FPE, há a predisposição desses atores serem mais governistas do que os seus colegas de partido.

Ao todo são 44 deputados federais confessionais que tendem a se comportar mais em direção as políticas de interesses do governo do que os 72 registrados como pertencentes à FPE. Um dos argumentos, por exemplo, que sustenta essa afirmação de que eles teriam essa propensão ao individualismo é o seu afastamento em relação à média geral de votos entre aqueles que não são religiosos, além, é claro, do pouco impacto dos partidos políticos na estruturação da atuação dos mesmos.

É válido lembrar que nossa análise diz respeito unicamente aos componentes da FPE, a nosso ver, pelo menos no que tange a comportamentos em questões seculares, têm demonstrado tendências egotrópicas em favor do governo - principalmente levando-se em consideração que o Executivo é o grande detentor de benefícios que podem ser utilizados estrategicamente como moeda de troca.

Conforme as médias registradas pela Tabela 3, os partidos com adeptos da FPE que mais possuem disposição em apoiar o Executivo são: o Partido Renovador Trabalhista Brasileiro (PRTB), o Partido Comunista do Brasil (PCdoB), o Partido Social Liberal (PSL), o Partido do Movimento Democrático Brasileiro (PMDB) e o Partido Trabalhista Brasileiro (PTB). 
Tabela 3 - Taxa média de apoio ao Executivo por partido e FPE

\begin{tabular}{|c|c|c|c|}
\hline \multicolumn{3}{|c|}{ Partido } & \multirow{2}{*}{$\frac{\text { Média }}{0,65}$} \\
\hline$\overline{\mathrm{PT}}$ & $\overline{\mathrm{FPE}}$ & Não & \\
\hline & & Sim & 0,61 \\
\hline \multirow[t]{2}{*}{ PRTB } & \multirow[t]{2}{*}{ FPE } & Não & - \\
\hline & & $\operatorname{Sim}$ & 0,26 \\
\hline \multirow[t]{2}{*}{ PCdoB } & \multirow[t]{2}{*}{ FPE } & Não & - \\
\hline & & Sim & 0,49 \\
\hline \multirow[t]{2}{*}{ PSB } & \multirow[t]{2}{*}{ FPE } & Não & 0,62 \\
\hline & & Sim & - \\
\hline \multirow[t]{2}{*}{$\mathrm{PP}$} & \multirow[t]{2}{*}{ FPE } & Não & 0,53 \\
\hline & & Sim & 0,51 \\
\hline \multirow[t]{2}{*}{ PTC } & \multirow[t]{2}{*}{ FPE } & Não & 0,51 \\
\hline & & $\operatorname{Sim}$ & 0,45 \\
\hline \multirow[t]{2}{*}{$\overline{\text { PSL }}$} & \multirow[t]{2}{*}{ FPE } & Não & - \\
\hline & & Sim & 0,61 \\
\hline \multirow[t]{2}{*}{ PMDB } & \multirow[t]{2}{*}{ FPE } & Não & 0,50 \\
\hline & & Sim & 0,60 \\
\hline \multirow[t]{2}{*}{ PTB } & \multirow[t]{2}{*}{ FPE } & Não & 0,49 \\
\hline & & Sim & 0,51 \\
\hline \multirow{2}{*}{ PRB } & \multirow{2}{*}{ FPE } & Não & 0,13 \\
\hline & & Sim & 0,60 \\
\hline \multirow[t]{2}{*}{ PSD } & \multirow[t]{2}{*}{ FPE } & Não & 0,45 \\
\hline & & Sim & 0,48 \\
\hline \multirow{2}{*}{ PSC } & \multirow{2}{*}{ FPE } & Não & 0,53 \\
\hline & & Sim & 0,44 \\
\hline PTdoB & FPE & Não & 0,24 \\
\hline & & Sim & 0,52 \\
\hline PRP & FPE & Não & 0,41 \\
\hline & & $\operatorname{Sim}$ & - \\
\hline PMN & FPE & Não & 0,53 \\
\hline & & Sim & - \\
\hline PDT & FPE & Não & 0,53 \\
\hline & & $\operatorname{Sim}$ & 0,70 \\
\hline PHS & FPE & Não & 0,67 \\
\hline & & Sim & - \\
\hline$\overline{P R}$ & FPE & Não & 0,49 \\
\hline & & $\operatorname{Sim}$ & 0,49 \\
\hline PV & FPE & Não & 0,45 \\
\hline & & Sim & 0,64 \\
\hline PPS & FPE & Não & 0,27 \\
\hline & & $\operatorname{Sim}$ & - \\
\hline PSOL & $\overline{F P E}$ & Não & 0,41 \\
\hline & & Sim & - \\
\hline DEM & FPE & Não & 0,22 \\
\hline & & Sim & 0,18 \\
\hline PSDB & $\overline{F P E}$ & Não & 0,21 \\
\hline & & Sim & 0,33 \\
\hline
\end{tabular}


Por outro lado, embora também possa ser considerado fruto da tendência egotrópica, não podemos dizer o mesmo do comportamento dos religiosos nas questões valorativas, onde eles parecem não demonstrar interesse em manter o compromisso com as orientações do Executivo (ver Tabela 4). Nesta ocasião, diametralmente oposta à primeira, a estratégia parece ser muito mais motivada em função da capitalização do status de defensor das bandeiras religiosas junto ao eleitorado confessional do que propriamente as possíveis benesses oriundas da Presidência.

Tabela 4 - Taxa média de apoio ao Executivo nas questões confessionais segundo situação/oposição e FPE

\begin{tabular}{|c|c|c|c|c|c|}
\hline & & & & & Média \\
\hline \multirow{4}{*}{ FPE } & \multirow[b]{2}{*}{ Não } & \multirow[b]{2}{*}{ Posição } & Oposição & Ind_FPE & 0,10 \\
\hline & & & Situação & Ind_FPE & 0,56 \\
\hline & \multirow[b]{2}{*}{ Sim } & \multirow[b]{2}{*}{ Posição } & Oposição & Ind_FPE & 0,00 \\
\hline & & & Situação & Ind_FPE & 0,02 \\
\hline $4 \pi$ & pr & & & & \\
\hline
\end{tabular}

De acordo com a Tabela 4, isso fica ainda mais evidente quando visualizamos a comparação entre a taxa média de apoio dos parlamentares que pertencem à situação. $\mathrm{O}$ Ind_FPE neste caso possui uma diferença de praticamente 0,5 pontos entre à FPE e os demais políticos. Isto é, quase não há apoio algum às pretensões do Executivo. O que, além de revelar a força dos valores religiosos na determinação do comportamento parlamentar, demostra peremptoriamente o nível de coesão, articulação e homogeneidade existente entre os adeptos da Frente quando se trata de questões de interesse religioso.

Além do mais, esse tipo de comportamento dá-nos a entender que, aumentando-se o âmbito de interesse e de membros entre os evangélicos, é grande a possibilidade de discordância não apenas para com as orientações político-partidárias como também para com o Poder Executivo. Neste caso, considerando que eles não parecem se importar muito com os riscos políticos envolvidos de um posicionamento declarado contra o detentor dos benefícios. 
No que tange aos pontos reduzidos às votações de ordem confessional, a tendência é essa; posto que os partidos políticos não demonstram possuir capacidade para resolver o problema da ação coletiva entre os deputados religiosos. Diante disso, eles preferem na maioria das vezes não seguir as orientações político-partidárias definidas a priori por seus próprios líderes. Tanto é verdade que a melhor média de apoio ao governo veio daqueles que seguiram suas lideranças partidárias na Câmara, a saber, os 0,56 pontos entre os integrantes da situação que não pertencem à FPE.

Vale ainda destacar que os partidos mais procurados pelos políticos e igrejas são aqueles que mais possuem coesão nos dados entre quem pertence e quem não pertence à FPE (ver Tabela 6). Essa correlação é explicada pela liberdade ou orientação com que os partidos apresentam diante de uma votação nominal em plenário.

Com exceção do Partido da República (PR), que possui 11 deputados em seus quadros, há congruência significativa entre as médias dos integrantes do Partido Social Cristão (PSC) e do Partido Republicano Brasileiro (PRB). Em ambos os casos, todos os deputados, incluindo tanto os filiados quanto os não filiados à FPE, possuem média zero quanto ao posicionamento diante do governo. A estratégia desses partidos é permitir que os parlamentares se posicionem conforme seus próprios interesses, isto é, aproximando-os de suas bases eleitorais predominantemente confessionais, o que acaba favorecendo-os eleitoralmente.

Como efeito, os parlamentares da FPE seguem individualmente seus próprios interesses, ou seja, votam de acordo com a possibilidade de maximizar seus ganhos eleitorais em detrimento da orientação dos líderes partidários. Em votações nominais carregados de carga valorativa, a maioria pertencente à FPE é esmagadoramente contraria as orientações do governo, inclusive - conforme a Tabela 5 -, entre aqueles que pertencem à situação. Nestes momentos, nem a força dos mecanismos centralizadores do congresso são capazes de impedir contrariedade tão intensa. Isto porque o maior interessado em questões valorativas tende a ser o eleitorado confessional que incentiva o seu player a não seguir as indicações partidárias. Lembrando que as questões confessionais são temáticas que interessam diretamente as principais lideranças evangélicas.

Tabela 5 - Taxa média de apoio ao Executivo nas questões confessionais segundo partido e FPE

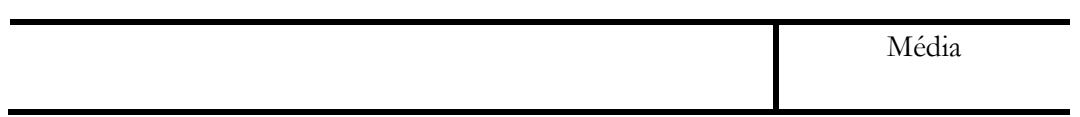




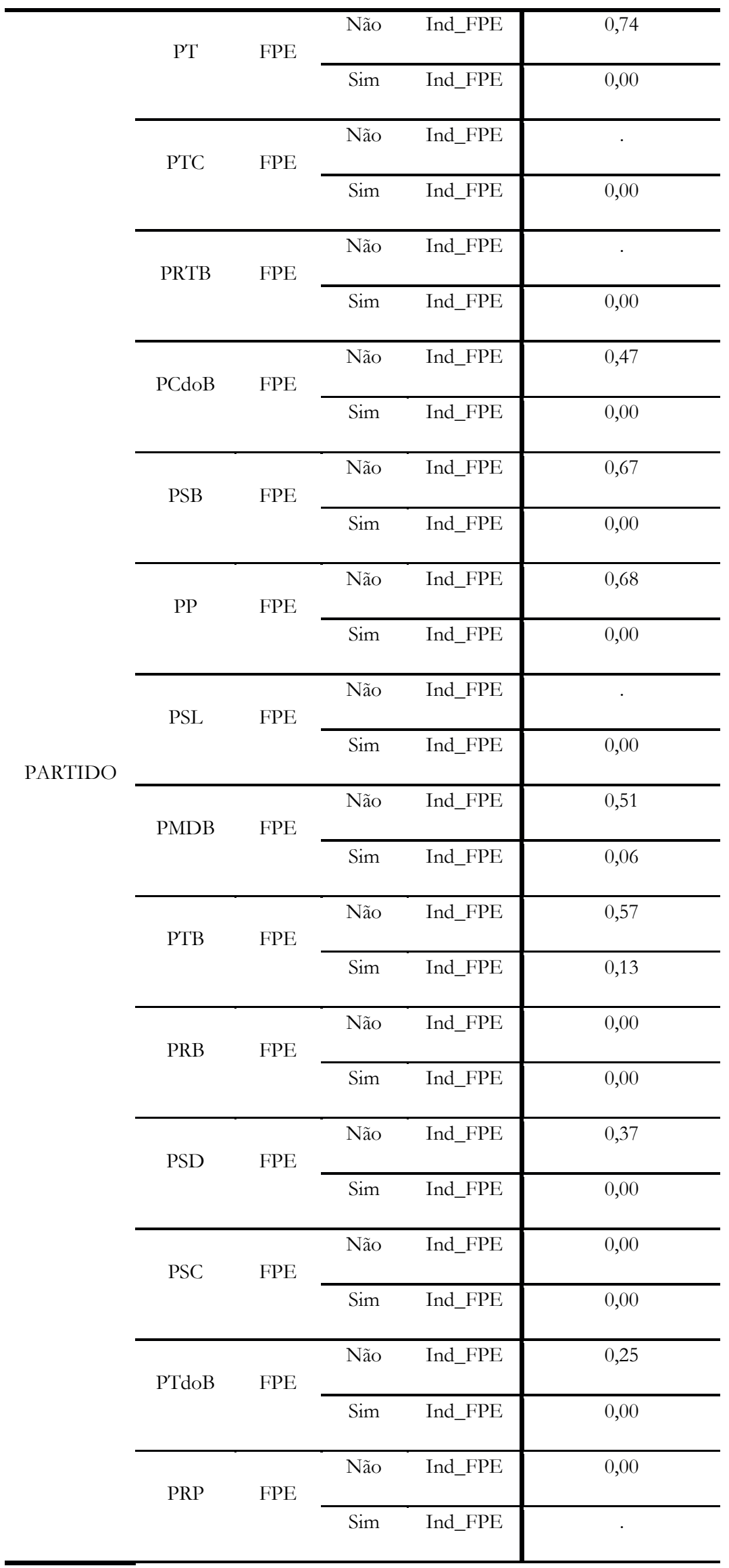




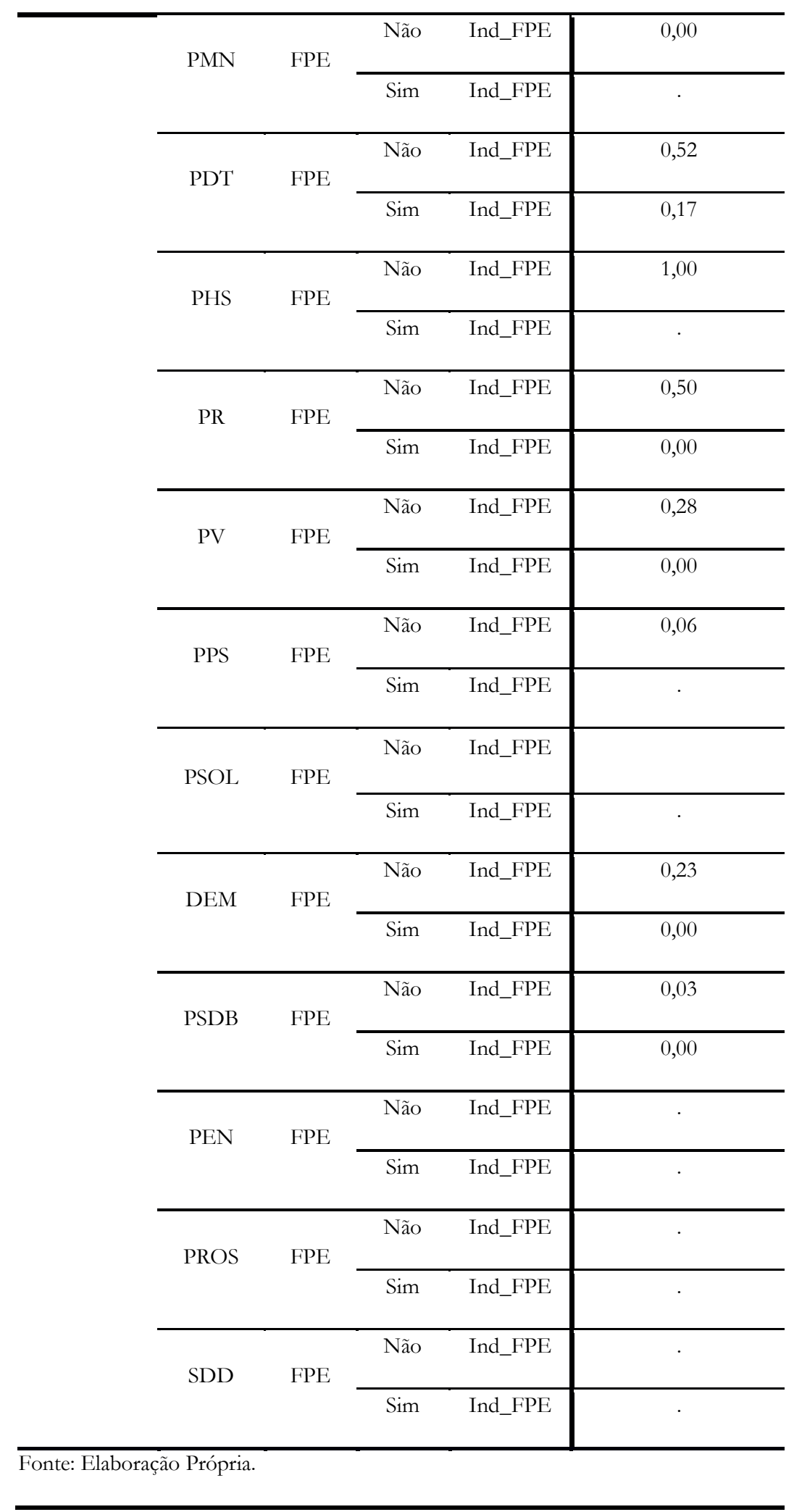

Como já dito, com exceção das votações em plenário de cunho valorativo, há tendência pró-governo entre a maioria dos integrantes da FPE. Porém, quais são as diferenças comportamentais de um grupo para o outro em relação à presidência? Isto é, 
existem diferenças na forma como a bancada vota tendo como base o grupo religioso que um determinado parlamentar pertence?

Conforme a Tabela 6, verifica-se não há um tipo de padrão de comportamento específico. Eles são bem diversos na maneira com que se posicionam diante dos interesses de governo. Desses, isolando-se somente os grandes grupos religiosos, a neopentecostal Universal é a que mais tende a votar segundo as pretensões da presidência $(0,62)$, seguida de longe pela pentecostal Assembleia de Deus $(0,48)$ e pela histórica Batista $(0,43)$.

Em relação aos grupos menores, os que menos tendem a votar de acordo com os interesses da presidência são os luteranos $(0,15)$ e os parlamentares da pentecostal e sectária Cristã do Brasil $(0,23)$. Ao passo que os que mais tendem a apoiar são os parlamentares da Presbiteriana Renovada $(0,79)$, do Brasil para Cristo $(0,67)$ e da Cristã Evangélica $(0,63)$.

Tabela 6 - Taxa média de apoio ao Executivo nas questões seculares segundo os grupos que compõem a Frente Parlamentar Evangélica

\begin{tabular}{c|c}
\hline \multirow{2}{*}{ Filiação Religiosa } & Indicador Final \\
\cline { 2 - 2 } & Média \\
\hline Assembleia de Deus & 0,48 \\
\hline Batista & 0,43 \\
\hline Universal do Reino de Deus & 0,62 \\
\hline Presbiteriana & 0,51 \\
\hline Presbiteriana Independente & 0,50 \\
\hline Evangelho Quadrangular & 0,40 \\
\hline Internacional da Graça de Deus & 0,48 \\
\hline Comunidade Evangélica Sara Nossa Terra & 0,46 \\
\hline Não Declarado & 0,50 \\
\hline Metodista & 0,55 \\
\hline Cristã Maranata & 0,54 \\
\hline Batista Solidária & 0,57 \\
\hline Batista Getsêmani & 0,45 \\
\hline Batista Nacional & 0,60 \\
\hline Batista Independente & 0,62 \\
\hline Batista Caminho das Árvores & 0,48 \\
\hline Presbiteriana Renovada & 0,79 \\
\hline Luterana & 0,15 \\
\hline Renascer & 0,54 \\
\hline Nova Vida & 0,58 \\
\hline Cristã Evangélica & 0,63 \\
\hline O Brasil para Cristo & 0,67 \\
\hline Cristã do Brasil & 0,23 \\
\hline Mundial do Poder de Deus & 0,53 \\
\hline Frente Parlamentar Evangélica/FPEBRASIL & \\
\hline
\end{tabular}

Os mais significativos dentre esses casos são sem dúvida os parlamentares ligados a Universal do Reino de Deus. Uma vez que são, de longe, os mais articulados politicamente, inclusive em torno de partidos específicos e delimitados, na maneira de posicionar-se em 
determinadas questões. Dado o ínfimo indicador geral entre todos os partidos no que diz respeito à média de apoio à Presidência, podemos considerar que a pontuação alcançada pelos parlamentares da IURD é extremamente relevante, em que pese, por outro lado, seja feito uma ressalva: os resultados desses dados estão diretamente relacionados ao fato deles permanecerem ao mesmo partido, o PRB. Saber em que medida os parlamentares estão localizados com base em suas ligações religiosas é interessante, mas deve-se tomar certos cuidados.

\section{CONSIDERAÇÕES FINAIS}

Neste trabalho procuramos compreender em que medida os parlamentares da Frente Parlamentar Evangélica têm se comportado diante das orientações da Presidência. Concluímos, segundo os modelos teóricos apresentados, que há uma tendência tênue por parte dos políticos confessionais em manter posição patogênica e egotrópica em relação ao funcionamento do processo legislativo. Identificamos que os parlamentares confessionais possuem tendência comportamental egotrópica tanto em questões seculares quanto em questões confessionais. Com a salvaguarda de que, nas votações confessionais nem o fato do governo deter sobre si os principais benefícios institucionais e mecanismos, fazem com que os mesmos mantenham o suposto compromisso político e a tendência favorável.

Assim, tanto nas questões seculares quanto nas valorativas, o que foi observado no padrão de votações parece-nos claro afirmar de que há um esvaziamento dos partidos políticos na estruturação da ação comportamental da maior parte dos parlamentares evangélicos. No caso específico das votações seculares, o que foi possível perceber é que entre eles a predisposição em votar segundo as orientações da Presidência independe de posições político-partidárias. Neste ponto, inclusive, pôde-se notar até setores da oposição pertencentes à FPE tendentes as orientações do Executivo.

A despeito de todos os incentivos institucionais que centralizam a decisão na mão dos líderes partidários, e que, de certa forma, reduz o campo de atuação dos parlamentares, o que parece plausível dizer é que há disposição, por parte do political religious, em maximizar suas possibilidades votando de acordo com a agenda do governo. Nesse cenário, o parlamentar confessional possui comportamento pessoal e descentralizado influenciado pelas regras eleitorais e que assim o faz motivado pelos interesses em sua reeleição. 
Porém, no caso das votações confessionais, embora o comportamento religioso não seja considerado menos egotrópico do que nas votações seculares, a orientação do parlamentar é terminantemente contrária aos interesses do Executivo. Isso ocorre, ao nosso entender, pelo fato de que o parlamentar age ambicionando exclusivamente os seus ganhos junto a sua base eleitoral, considerada predominantemente conservadora.

Neste caso, inclusive, há congruência muito coesa das médias entre os adeptos da FPE, o que revela a força dos interesses religiosos no condicionamento comportamental. Aliás, parece que nem mesmo os custos políticos de tal posicionamento são capazes de restringir o nível de dissonância entre eles e o Executivo.

Além disso, identificamos que há padrão na escolha das agremiações partidárias a partir do vínculo religioso do parlamentar. Como reflexo disso, por exemplo, temos o PRB abrigando parlamentares filiados à Igreja Universal do Reino de Deus. No mais, sustentamos que os parlamentares filiados a Frente Parlamentar Evangélica, tanto nas questões confessionais, quanto nas questões seculares, têm se revelado instáveis e altamente inconstantes em seus posicionamentos na Câmara dos Deputados.

\section{REFERÊNCIAS}

AMES, B. 1995. Electoral rules, constituency pressures, and pork barrel: bases of voting in the brazilian congress. The Journal of Politics, vol. 57, no 2, p. 324-343.

AMES, B. 2003. Os entraves da democracia no Brasil. Rio de Janeiro, FGV Editora.

AMORIM, O. 2002. Presidential cabinets, electoral cycles, and coalition discipline in Brazil. In: MORGENSTERN, S; NACIF, B (eds.). Legislative Politics in Latin America. Cambridge, Cambridge University Press, p. 48-78.

AMORIM, O.; SANTOS, F. 2001. The executive connection: presidentially-defined factions and party discipline in Brazil. Party Politics, v. 7, n. 2, p. 213-234.

BAQUERO, M.; AMORIM, M. 2007. Cultura política fragmentada: o papel do capital social na democratização brasileira. Sociedade e Cultura, v. 7, n. 1.

BORGES, T. 2010. Identidade política evangélica e os deputados estaduais brasileiros. Perspectivas: Revista de Ciências Sociais, v. 35, p. 213-234. 
BOWLER, S. 2000. Parties in legislatures: two competing explanations. In: DALTON, R.; WATTENBERG, M. (eds.). Parties without partisans: political change in advanced industrial democracies. Oxford, Oxford University Press, p. 157-179.

CAMPOS, L. 2005. As origens norte-americanas do pentecostalismo brasileiro: observações sobre uma relação ainda pouco avaliada. Revista USP, n. 67, p. 100-115.

CERVI, E. 2009. Produção legislativa e conexão eleitoral na Assembleia Legislativa do Estado do Paraná. Revista de Sociologia e Política, v. 17, n. 32, p. 159-177.

COX, G. 1987. The efficient secret: the cabinet and the development of political parties in victorian England. Cambridge, Cambridge University Press.

COX, G; McCUBBINS, M. 1993. Legislative leviathan: party government in the House. Berkeley, University of California Press.

DOWNS, A. 1999. Uma teoria econômica da democracia. São Paulo, Edusp.

FIGUEIREDO, A.; LIMONGI, F. 1995. Mudança constitucional, desempenho legislativo e consolidação Institucional. Revista Brasileira de Ciências Sociais, vol 10, nº 29, p. 175-200.

FIGUEIREDO, A.; LIMONGI, F. 1997. Presidential power and party behavior in the legislature. Trabalho apresentado em encontro da Latin American Studies Association - LASA, Guadalajara, México.

FIGUEIREDO, A.; LIMONGI, F. 1999. Executivo e Legislativo na nova ordem constitucional. São Paulo, Editora FGV.

FIGUEIREDO, A.; LIMONGI, F. 2000. Presidential power, legislative organization and party behavior in Brazil. Comparative Politics, New York, v. 32, n. 2, p. 151-170.

FIGUEIREDO, A.; LIMONGI, F. 2002. Incentivos eleitorais, partidos políticos e política orçamentária. Dados, v. 45, n. 2, p. 303-339.

FIGUEIREDO, A.; LIMONGI, F. 2005. Processo orçamentário e comportamento legislativo: emendas individuais, apoio ao Executivo e programas de governo. Dados, v. 48, n. 004, p. 737-776.

HAGGARD, S. 1995. The Reform of the State in Latin America. Trabalho apresentado na Annual World Bank Conference on Development in Latin America and Caribbean. Rio de Janeiro.

HAGGARD, S; KAUFMAN, R. 1992. The politics of economic adjustment: international shocks, distributive conflicts and the State. Princeton, Princeton University Press.

LAMOUNIER, B. 1989. Partidos e utopias: O Brasil no limiar dos anos 80. São Paulo, Loyola.

MAINWARING, S. 1999. Rethinking party systems in the third wave of democratization: the case of Brazil. Stanford, Stanford University Press. 
MAINWARING, S; SCULLY, T. 1995. Building democratic institutions: party systems in Latin America. California, Stanford University Press.

MAINWARING, S; SHUGART, M. 1997. Presidentialism and democracy in Latin America. Cambridge, Cambridge University Press.

MAYHEW, D. 1974. Congress: the electoral connection. New Haven, Yale University Press.

MENEGHELLO, R. 1998. Partidos e governos no Brasil contemporâneo (1985-1997). São Paulo: Paz e Terra.

NEIVA, P. 2011. Coesão e disciplina partidária no Senado Federal. Dados, v. 54, n. 1, p. 289318.

PEREIRA, C; MUELLER, B. 2000. Uma teoria da preponderância do Poder Executivo. O sistema de comissões no Legislativo brasileiro. Revista Brasileira de Ciências Sociais, vol. 15, $\mathrm{n}^{\circ}$ 43 , p. $45-67$.

PEREIRA, C; MUELLER, B. 2002. Comportamento estratégico em presidencialismo de coalizão: as relações entre Executivo e Legislativo na elaboração do orçamento brasileiro. Dados, v. 45, n. 2, p. 265-301.

PEREIRA, C; MUELLER, B. 2003. Partidos fracos na arena eleitoral e partidos fortes na arena legislativa: a conexão eleitoral no Brasil. Dados, vol. 46, n. 4, p. 735-771. 